УДК 542.06:543.51:543.645

\title{
МАСС-СПЕКТРОМЕТРИЧЕСКОЕ ИССЛЕДОВАНИЕ ПРОЦЕССОВ САМОАССОЦИАЦИИ МОЛЕКУЛ ГЛИЦИРРЕТИНОВОЙ КИСЛОТЫ
}

\author{
(C) С.Н. Борисенко, А.В. Лекарь, Е.В. Ветрова, О.В. Филонова, Н.И. Борисенко \\ НИИ физической и органической химии Южного федерального \\ университета, пр. Стачки, 194/2, Ростов-на-Дону, 344090 (Россия), \\ e-mail: boni@ipoc.rsu.ru
}

\begin{abstract}
Масс-спектрометрия с ионизацией электрораспылением использована для изучения процессов формирования автоассоциатов агликона глицирризиновой кислоты - глицирретиновой кислоты (ГЛК). На примере стереоизомеров глицирретиновой кислоты впервые показано, что оба стереоизомера по аналогии с тритерпеновыми сапонинами со свободными карбоксильными группами могут образовывать автоассоциаты. Способность глицирретиновой кислоты образовывать самоассоциаты подтверждают показания масс-спектров. Установлено, что ионизация ассоциатов ГЛК с образованием аниона происходит достаточно слабо. Ионизация ГЛК в режиме положительных ионов происходит эффективно и позволяет регистрировать многомерные структуры от 1 до 8 молекул для 18 $\alpha$-ГЛК и от 1 до 9 молекул для $18 \beta$-ГЛК. Наиболее полная картина по строению ассоциатов ГЛК и их устойчивости представлена в масс-спектрах

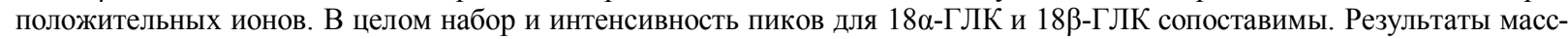

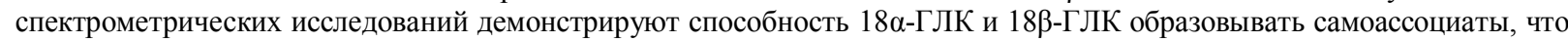
указывает на высокий потенциал глицирретиновой кислоты в образовании нековалентных взаимодействий при формировании супрамолеклярных комплексов. Стереоизомеры глицирретиновой кислоты по аналогии с сапонинами солодки и плюща могут стать потенциальной основой для синтеза нового поколения нековалентных молекулярных комплексов и новых высокоэффективных лекарственных субстанций за счет как возможного улучшения биодоступности, так и возможных синергетических эффектов.
\end{abstract}

Ключевые слова: самоассоциация, глицирретиновая кислота, глицирризиновая кислота, масс-спектрометрия, ионизация электрораспылением, супрамолекулярные комплексы.

Работа выполнена при финансовой поддержке гранта РФФИ 13-03-01318, 13-03-12271 офи_м.

\section{Введение}

Лекарственные препараты на основе модифицированных природных соединений часто превышают исходные вещества по эффективности. В связи с этим исследование химии биологически активных веществ на основе вторичных растительных метаболитов стало важнейшим направлением в современной медицинской химии и в настоящее время являются объектом многочисленных исследований во всем мире.

Борисенко Сергей Николаевич - старший научный сотрудник, кандидат химических наук,

e-mail: sn.borisenko@gmail.com

Лекарь Анна Владимировна - младший научный сотрудник лаборатории суб- и суперкритических флюидных технологий, e-mail: lekarann@mail.ru

Ветрова Елена Владимировна - старший научный сотрудник лаборатории суб- и суперкритических флюидных технологий, кандидат биологических наук, e-mail: vetrova-ev@yandex.ru

Филонова Ольга Владимировна - младший научный сотрудник лаборатории суб- и суперкритических флюидных технологий, e-mail: fokysnik007@mail.ru Борисенко Николай Иванович - главный научный сотрудник лаборатории суб- и суперкритических флюидных технологий, доктор химических наук, e-mail: boni@ipoc.rsu.ru
Так, например, глицирризиновая кислота - один из основных растительных метаболитов корней солодки голой Glycyrrhiza glabra L. и Gl. uralensis $F$., демонстрирует огромный потенциал для синтеза новых высокоэффективных фармацевтических соединений и субстанций на ее основе $[1,2]$. Агликон ГК - глицирретиновая кислота (ГЛК) также оказалась в последние несколько лет предметом многочисленных исследований и приложений благодаря своей высокой противовоспалительной, противоязвенной, антиаллергической, гепатопротекторной и противовирусной активности [3-6].

Поскольку глицирретиновая кислота является агликоном глицирризиновой кислоты и имеет

\footnotetext{
* Автор, с которым следует вести переписку.
} 
аналогичный с ней молекулярный скелет, то можно ожидать, по аналогии с супрамолекулярными фармсубстанциями глицирризиновой кислоты [2], проявления новых свойств у супрамолекулярных комплексов, создаваемых на основе глицирретиновой кислоты -за счет как возможного улучшения биодоступности [2], так и возможных синергетических эффектов [7].

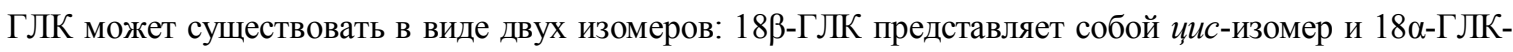
транс-изомер (рис. 1). Молекулам изомеров ГЛК также присуще наличие различных реакционных центров (-СООН и -ОН), поэтому изомеры ГЛК, по аналогии с гликозидами ГК, могуг образовывать самоассоциаты. Однако до сих пор прямые доказательства существования таких молекулярных ансамблей отсутствуют.

Важно отметить, что ГЛК за счет возможности самоорганизации таких супрамолекулярных образований, так же, как и ГК, может связывать лекарственные субстанции в виде нековалентных молекулярных комплексов и, как следствие, давать новые фармацевтические субстанции.

В недавних работах авторов [8-11] показано, что масс-спектрометрия с ионизацией электрораспылением (EC-MC) позволяет быстро и надежно оценить возможности образования самоассоциатов тритерпеновых растительных метаболитов и изучить качественный состав образуемых полидентантных супрамолекулярных комплексов и их количественные характеристики.

Поэтому целью данной работы явилось изучение процессов самоассоциации изис- и транс-изомеров глицирретиновой кислоты методами масс-спектрометрии с ионизацией электрораспылением для последующей оценки возможностей создания и изучения супрамолекулярных комплексов глицирретиновой кислоты с фармацевтическими субстанциями.

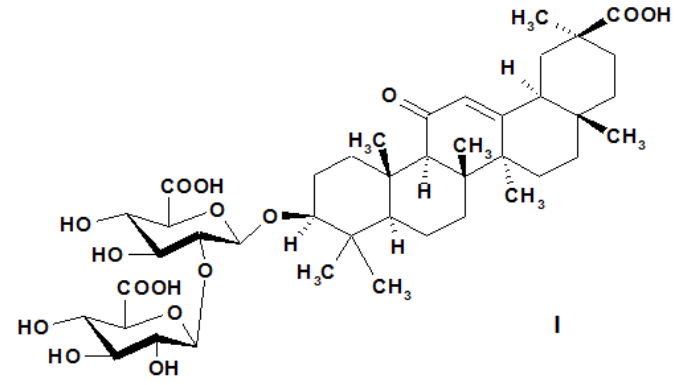

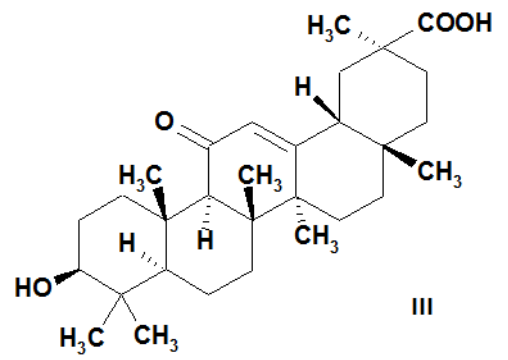

$3 \beta$-гидрокси-11-оксо-18 $\beta, 20 \beta$-олеан-12-ен-29- овая кислота (18 $\beta$ - ГЛК)

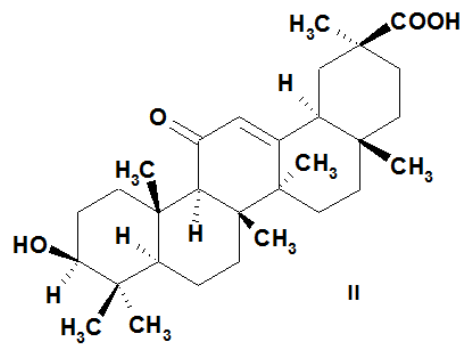

$3 \beta$-гидрокси-11-оксо-18 $\alpha, 20 \beta$-олеан-12-ен-29-овая

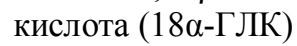

Рис. 1. Структурные формулы глицирризиновой кислоты I и стереоизомеров глицирретиновой кислоты $\left(\mathrm{C}_{30} \mathrm{H}_{46} \mathrm{O}_{4}\right), 18 \alpha$-ГЛК II и цис-изомер -

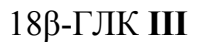

\section{Экспериментальная часть}

Масс-спектры ГЛК получены с использованием масс-спектрометра «Bruker Daltonics micrOTOF-Q». Ионизация молекул осуществлялась путем электрораспыления при введении пробы напрямую. Детектирование отрицательных и положительных ионов осуществлялось в интервале от 50 до 3000 Да с точностью не менее $1 \times 10^{-2}$ Да. Напряжение на капилляре распылителя $\pm 4200 \mathrm{~B}$, параметры газа-осушителя (азот «осч», 5 л/мин, $\left.200^{\circ} \mathrm{C}\right)$ и энергия ионов на квадруполе $(5,0$ эВ) оптимизированы для детектирования пиков ассоциатных ионов. Программное обеспечение micrOTOFcontrol TM2.2 использовано для анализа масс спектров. Все пики идентифицированы по значениям $\mathrm{m} / \mathrm{z}$ и соответствующим изотопным распределениям. Программа, моделирующая изотопные распределения, использована для верификации изотопных распределений, полученных экспериментально. 
Для исследований использовали $18 \alpha$-ГЛК и 18 -ГЛК производства Sigma. Для прямого ввода применяли растворы ГЛК в метаноле (фирма Merck, квалификация HPLC/MS) в концентрации 0,1 мг/мл.

\section{Результаты и обсуждение}

Эффективность образования самоассоциатов стереоизомеров ГЛК изучена в режиме генерации как отрицательных, так и положительных ионов. Результаты масс-спектрометрических исследований $18 \alpha-Г Л К ~$

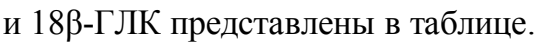

Основной пик $m / z$ 469,37 в масс-спектре отрицательных ионов как для $18 \alpha-Г Л К$, так и для $18 \beta$-ГЛК принадлежал депротонированной молекуле ГЛК $\left[\mathrm{M}^{\Gamma Л К}-\mathrm{H}\right]^{3}$. Зафиксирован депротонированный димер $\left[2 \mathrm{M}^{\text {ГЛК }}\right.$-Н], причем в случае $18 \beta$-ГЛК димер более устойчив, чем $18 \alpha$-ГЛК (интенсивность пика $m / z 939$ в 3 раза выше для 18ß-ГЛК). Только в случае $18 \beta$-ГЛК зафиксирован слабоинтенсивный пик $\mathrm{m} / \mathrm{z} 1410,14$ депротонированного тримера $\left[3 \mathrm{M}^{\Gamma л К}-\mathrm{H}\right]$. Полученные результаты указывают на то, что ионизация ассоциатов $18 \alpha$-ГЛК и $18 \beta$-ГЛК в анион происходит достаточно слабо, в масс-спектрах отрицательных ионов зафиксированы лишь однозарядные ионы.

В масс-спектре положительных ионов основной пик принадлежал протонированной молекуле ГЛК с $\mathrm{m} / \mathrm{z}$ 471,44. Помимо этого, присутствует группа пиков $\left(\mathrm{c} \mathrm{H}^{+}, \mathrm{Na}^{+}, \mathrm{K}^{+}\right)$для одно- и двузарядных ионов ГЛК. Так, формирование однозарядного катиона с $\mathrm{Na}^{+} \mathrm{m} / z$ 493,43 происходит в 2,8 раз эффективнее, чем с $\mathrm{K}^{+} \mathrm{m} / z$ 509,41. Также присутствует однозарядный пик $m / z$ 511,44 катионизированного натрием иона с включением одной молекулой воды $\left[\mathrm{M}^{\text {ГЛК }}+\mathrm{Na}+\mathrm{H}_{2} \mathrm{O}\right]^{+}$.

Двузарядные катионизированные мономеры представлены в массспектре отрицательных ионов достаточно широко. Особенно широко представлены катионы с калием. Так, наибольшей интенсивностью в ряду двузарядных мономеров обладает пик $m / z \quad 275,75 \quad(9,87)$ для иона $\left[\mathrm{M}^{\text {ГлК }}+2 \mathrm{~K}\right]^{2+}$. В 4 раза меньший по интенсивности наблюдали пик $\mathrm{m} / \mathrm{z}$ 267,73 , принадлежащий иону, катионизированному и $\mathrm{K}^{+}$, и $\mathrm{Na}^{+}$ $\left[\mathrm{M}^{\text {ГЛК }}+\mathrm{K}+\mathrm{Na}\right]^{2+}$. Принятие молекулы ГЛК с калием протона и воды приводит также к уменьшению устойчивости иона (в 2-3 раза уменьшается интенсивность относительно пика с двумя ионами калия). В целом эффективность ионизации катионизированных мономеров и соответствующий набор пиков для $18 \alpha$-ГЛК

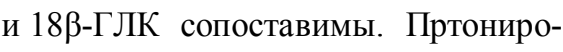
ванных двузарядных мономеров ГЛК в масс-спектрах не выявлено.

В масс-спектрах положительных ионов наблюдали одинаковый набор пиков, принадлежащих диме-

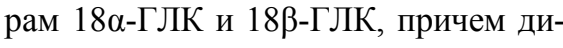
меры представлены в виде как одно-, так и двузарядных ионов.

Наибольшей интенсивностью обладает пик $m / z$ 941,87, принадлежащий однозарядному протониро-

Наличие и строение автоассоциатов стереоизомеров глицирретиновой кислоты

\begin{tabular}{|c|c|c|c|c|}
\hline \multirow{2}{*}{ Строение иона } & \multicolumn{2}{|c|}{$18 \alpha-Г Л К$} & \multicolumn{2}{|c|}{$18 \beta$-ГЛК } \\
\hline & $\mathrm{m} / \mathrm{z}$ & $\mathrm{I}, \%$ & $\mathrm{~m} / \mathrm{z}$ & $\mathrm{I}, \%$ \\
\hline$\left[\mathrm{M}^{\text {IJK }}-\mathrm{H}\right]^{-}$ & 469,37 & 100 & 469,39 & 100 \\
\hline$\left[2 \mathrm{M}^{\text {ГЛК }}-\mathrm{H}\right]^{-}$ & 939,75 & 13,75 & 939,77 & 42,22 \\
\hline$\left[3 \mathrm{M}^{\text {ГЛК }}-\mathrm{H}\right]^{-}$ & - & - & 1410,14 & 0,01 \\
\hline$\left[\mathrm{M}^{\Gamma Л \mathrm{~K}}+\mathrm{H}\right]^{+}$ & 471,44 & 100 & 471,44 & 100 \\
\hline$\left[\mathrm{M}^{\Gamma Л \mathrm{~K}}+\mathrm{Na}\right]^{+}$ & 493,42 & 36,88 & 493,43 & 46,88 \\
\hline$\left[\mathrm{M}^{\Gamma Л \mathrm{~K}_{+}}+\mathrm{K}\right]^{+}$ & 509,40 & 15,21 & 509,41 & 16,64 \\
\hline$\left[\mathrm{M}^{\Gamma Л \kappa}+\mathrm{Na}+\mathrm{H}_{2} \mathrm{O}\right]^{+}$ & 511,43 & 11,06 & 511,44 & 6,80 \\
\hline$\left[\mathrm{M}^{\Gamma Л \mathrm{~K}}+2 \mathrm{~K}\right]^{2+}$ & 275,72 & 7,94 & 275,75 & 9,87 \\
\hline$\left[\mathrm{M}^{\Gamma Л К}+\mathrm{K}+\mathrm{Na}\right]^{2+}$ & 267,73 & 1,95 & 267,73 & 2,43 \\
\hline$\left[\mathrm{M}^{\Gamma Л \mathrm{~K}}+\mathrm{K}+\mathrm{H}\right]^{2+}$ & 255,20 & 5,84 & 255,20 & 1,26 \\
\hline$\left[\mathrm{M}^{\Gamma Л \mathrm{~K}_{+}}+\mathrm{K}+\mathrm{H}_{2} \mathrm{O}+\mathrm{H}\right]^{2+}$ & 264,66 & 4,78 & 264,21 & 0,82 \\
\hline$\left[2 \mathrm{M}^{\Gamma л К}+\mathrm{H}\right]^{+}$ & 941,87 & 87,25 & 941,87 & 36,59 \\
\hline$\left[2 \mathrm{M}^{\Gamma Л \mathrm{~K}}+\mathrm{K}\right]^{+}$ & 979,83 & 7,25 & 979,83 & 8,13 \\
\hline$\left[2 \mathrm{M}^{\Gamma л \kappa}+2 \mathrm{~K}\right]^{2+}$ & 510,41 & 3,24 & 510,41 & 3,47 \\
\hline$\left[2 \mathrm{M}^{\Gamma Л K}+\mathrm{K}+\mathrm{H}\right]^{2+}$ & 490,41 & 12,59 & 490,42 & 10,92 \\
\hline$\left[2 \mathrm{M}^{\Gamma Л \kappa}+\mathrm{Na}+\mathrm{H}\right]^{2+}$ & 482,42 & 2,28 & 482,42 & 2,43 \\
\hline$\left[2 \mathrm{M}^{\Gamma Л K}+\mathrm{K}+\mathrm{Na}\right]^{2+}$ & 502,94 & 0,88 & 502,95 & 1,09 \\
\hline$\left[2 \mathrm{M}^{\Gamma Л К}+\mathrm{K}+\mathrm{H}+\mathrm{H}_{2} \mathrm{O}\right]^{2+}$ & 499,42 & 2,17 & 499,43 & 1,33 \\
\hline$\left[2 \mathrm{M}^{\Gamma Л \mathrm{~K}}+2 \mathrm{~K}+\mathrm{H}_{2} \mathrm{O}\right]^{2+}$ & 519,94 & 0,74 & 519,94 & 0,93 \\
\hline$\left[2 \mathrm{M}^{\Gamma Л К}+\mathrm{Na}\right]^{+}$и $\left[4 \mathrm{M}^{\Gamma Л К}+2 \mathrm{Na}\right]^{2+}$ & 963,85 & 23,60 & 963,86 & 19,71 \\
\hline$\left[3 \mathrm{M}^{\Gamma Л K}+\mathrm{Na}+\mathrm{H}\right]^{2+}$ & 717,64 & 2,84 & 717,65 & 2,43 \\
\hline$\left[3 \mathrm{M}^{\Gamma Л K}+\mathrm{K}+\mathrm{H}\right]^{2+}$ & 725,62 & 9,49 & 725,64 & 8,99 \\
\hline$\left[3 \mathrm{M}^{\Gamma Л \kappa}+2 \mathrm{Na}\right]^{2+}$ & 728,62 & 4,52 & 728,64 & 3,89 \\
\hline$\left[3 \mathrm{M}^{\Gamma Л \kappa}+\mathrm{Na}+2 \mathrm{H}_{2} \mathrm{O}+\mathrm{H}\right]^{2+}$ & 736,63 & 0,85 & 736,61 & 1,48 \\
\hline$\left[3 \mathrm{M}^{\Gamma Л К}+2 \mathrm{~K}\right]^{2+}$ & 744,61 & 0,18 & 744,62 & 0,23 \\
\hline$\left[3 \mathrm{M}^{\text {ГлК }}+\mathrm{Na}\right]^{+}$и $\left.6 \mathrm{M}^{\text {ГлК }}+2 \mathrm{Na}\right]^{2+}$ & 1434,28 & 17,22 & 1434,29 & 14,63 \\
\hline$\left[3 \mathrm{M}^{\text {ГлК }}+\mathrm{K}\right]^{+}$и $\left[6 \mathrm{M}^{\Gamma Л К}+2 \mathrm{~K}\right]^{2+}$ & 1450,25 & 2,56 & 1450,27 & 1,63 \\
\hline$\left[4 \mathrm{M}^{\Gamma Л К}+\mathrm{Na}+\mathrm{H}\right]^{2+}$ & 953,36 & 2,77 & 953,37 & 7,25 \\
\hline$\left[4 \mathrm{M}^{\Gamma Л \kappa}+\mathrm{K}+\mathrm{H}\right]^{2+}$ & 960,84 & 5,53 & 960,84 & 3,95 \\
\hline$\left[4 \mathrm{M}^{\Gamma Л \kappa}+\mathrm{K}+\mathrm{Na}\right]^{2+}$ & 971,85 & 1,99 & 971,89 & 2,09 \\
\hline$\left[4 \mathrm{M}^{\Gamma л \kappa}+\mathrm{Na}\right]^{+}$ & 1904,70 & 24,68 & 1904,68 & 11,04 \\
\hline$\left[4 \mathrm{M}^{\Gamma Л \kappa}+\mathrm{K}\right]^{+}$ & 1920,67 & 0,26 & 1920,69 & 0,37 \\
\hline
\end{tabular}
ванному димеру ГЛК $\left[2 \mathrm{M}^{\Gamma л К}+\mathrm{H}\right]^{+}$, 


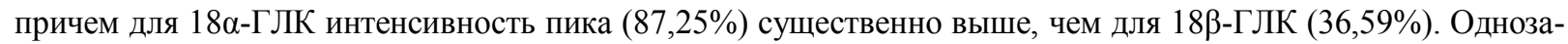
рядные димеры, катионизированные натрием $\left[2 \mathrm{M}^{\text {ГлК }}+\mathrm{Na}\right]^{+}$, также имели высокую интенсивность пика $m / z$

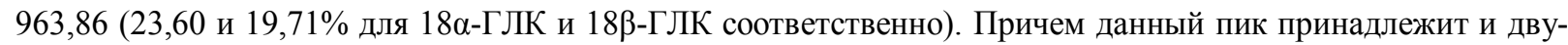
зарядному тетерамеру ГЛК с двумя катионами натрия $\left[4 \mathrm{M}^{\Gamma л К}+2 \mathrm{Na}\right]^{2+}$ или $\left[\left(2 \mathrm{M}^{\text {ГлК }}+\mathrm{Na}\right) \ldots\left(2 \mathrm{M}^{\text {ГлК }}+\mathrm{Na}\right)\right]^{2+}$. Интенсивность второго изотопного пика 964,35 составила порядка 5\%. Комплексы, катионизированные калием, представлены в виде одно- и двузарядного димера ГЛК $\left[2 \mathrm{M}^{\text {ГлК }}+\mathrm{K}\right]^{+}$с $m / z 979.83$ и $\left[2 \mathrm{M}^{\text {ГЛК }}+2 \mathrm{~K}^{2+} \mathrm{c}\right.$ $m / z$ 510.41. Катионы димера с калием и натрием $\left[2 \mathrm{M}^{\text {ГлК }}+\mathrm{K}+\mathrm{Na}\right]^{2+}$ представлены в виде пика $m / z 502.95$ с интенсивностью $1 \%$.

Формирование двузарядных димеров с одним катионом и протоном, таких как $\left[2 \mathrm{M}^{\text {Глк }}+\mathrm{K}+\mathrm{H}\right]^{2+}$ и $\left[2 \mathrm{M}^{\text {ГлК }}+\mathrm{Na}+\mathrm{H}\right]^{2+}$, представлено пиками $\mathrm{m} / z$ 490,41 и $\mathrm{m} / \mathrm{z} 482,42$, причем комплекс с калием 4,5 раза более устойчив, чем с натрием. Присоединение молекулы воды также формирует комплексы $\left[2 \mathrm{M}^{\text {Глк }}+2 \mathrm{~K}+\mathrm{H}_{2} \mathrm{O}\right]^{2+} \mathrm{c}$ $m / z 519.94$ и $\left[2 \mathrm{M}^{\text {ГлК }}+\mathrm{K}+\mathrm{H}+\mathrm{H}_{2} \mathrm{O}\right]^{2+}$ с $m / z$ 499.43, но интенсивность соответствующих пиков невысока.

Тримеры ГЛК представлены в масс-спектрах пиками катионизированных натрием и калием одноза-

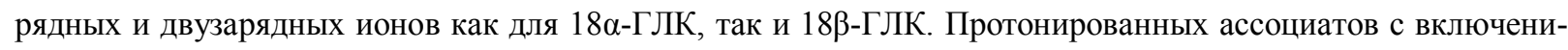
ем 3-х и более молекул ГЛК в масс-спектрах не обнаружено. Наиболее устойчивыми оказались однозаряд-

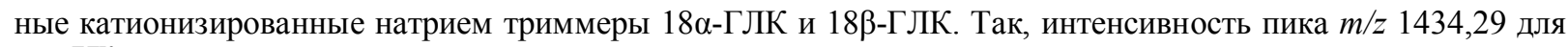
$\left[3 \mathrm{M}^{\text {Глк }}+\mathrm{Na}\right]^{+}$в 3,8 раз выше, чем для пика $m / z$ 728,64 двузарядного катионизированного натрием иона $\left[3 \mathrm{M}^{\Gamma л \kappa}+2 \mathrm{Na}\right]^{2+}$. В случае комплексов с калием интенсивность пика $\mathrm{m} / \mathrm{z} 1450,27$ однозарядного иона $\left[3 \mathrm{M}^{\Gamma л \kappa}+\mathrm{K}\right]^{+}$в 7 раз выше, чем $\mathrm{m} / \mathrm{z} 744,62$ двузарядного иона $\left[3 \mathrm{M}^{\Gamma л \kappa}+2 \mathrm{~K}\right]^{2+}$. Причем пики для тримеров ГЛК, катионизированных натрием ионов, значительно выше, чем для аналогичных ионов, катионизированных калием (в 11,8 раз в случае однозарядных и в 16,9 раз в случае двузарядных ионов). Идентифицированы пики $m / z 725,64(8,99 \%)$ и $m / z 717,65(2,43 \%)$, принадлежащие $\left[3 \mathrm{M}^{\text {ГлК }}+\mathrm{K}+\mathrm{H}\right]^{2+}$ и $\left[3 \mathrm{M}^{\text {Глк }}+\mathrm{Na}+\mathrm{H}\right]^{2+}$ соответственно. Двузарядный тример ГЛК с двумя молекулами воды $\left[3 \mathrm{M}^{\Gamma л \kappa}+\mathrm{Na}^{2} 2 \mathrm{H}_{2} \mathrm{O}+\mathrm{H}\right]^{2+}$ представлен

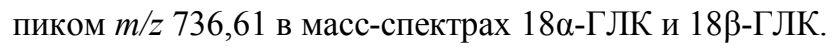

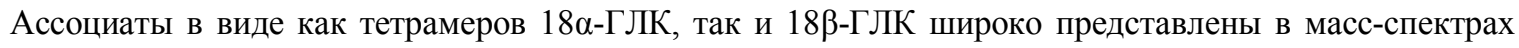
положительных ионов. Катионизированные тетрамеры ГЛК представлены несколькими пиками: $m / z$ 1904,70 для $\left[4 \mathrm{M}^{\Gamma л \kappa}+\mathrm{Na}\right]^{+}$и $m / z 1920,69(0,37 \%)$ для $\left[4 \mathrm{M}^{\Gamma л К}+\mathrm{K}\right]^{+}$, причем комплексы с натрием устойчивей,

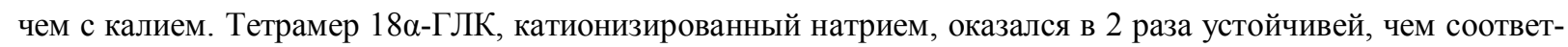
ствующий тетрамер 18ß-ГЛК. Двузарядные комплексы тетрамеров ГЛК представлены пиками $m / z 953,37$ для $\left[4 \mathrm{M}^{\text {ГлК }}+\mathrm{Na}+\mathrm{H}\right]^{2+}$ и $\mathrm{m} / z$ 971,89 для иона $\left[4 \mathrm{M}^{\text {Глк }}+\mathrm{K}+\mathrm{H}\right]^{2+}$. Аналогично предыдущим случаям в массспектре идентифицирован ион $\left[4 \mathrm{M}^{\text {ГлК }}+\mathrm{K}+\mathrm{Na}\right]^{2+}$ с соответствующим пиком $m / z$ 971,89.

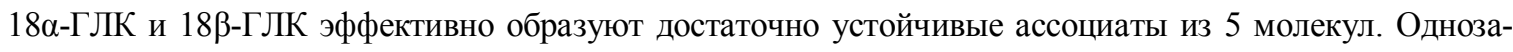
рядный ион, катионизированный калием пентамер ГЛК, представлен слабоинтенсивным пиком $m / z 2391,05$. Среди двузарядных ионов наибольшей интенсивностью обладает пик $m / z$ 1196,06, сответствующий иону $\left[5 \mathrm{M}^{\Gamma л К}+\mathrm{K}+\mathrm{H}\right]^{2+}$. Ионы $\left[5 \mathrm{M}^{\text {ГлК }}+\mathrm{K}+\mathrm{Na}\right]^{2+}$ и $\left[5 \mathrm{M}^{\text {ГлК }}+2 \mathrm{Na}\right]^{2+}$ также представлены в масс-спектре в виде пиков $m / z$

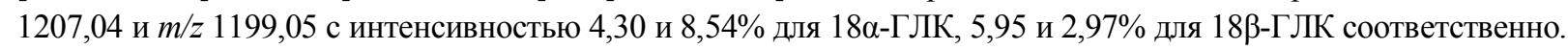

Ассоциты $18 \alpha$-ГЛК и 18ß-ГЛК, состоящие из 6 катионизированных молекул, представлены в масс-

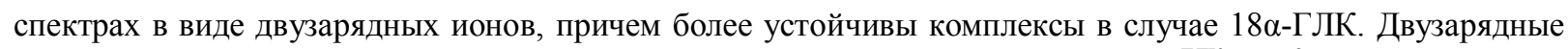
катионизированные комплексы ГЛК представлены пиками $m / z$ 1450,25 для [6М $\left.{ }^{\text {ГлК }}+2 \mathrm{~K}\right]^{2+}, m / z 1434,29$ для $\left[6 \mathrm{M}^{\text {ГлК }}+2 \mathrm{Na}\right]^{2+}$, а также $m / z 1431,35$ для иона $\left[6 \mathrm{M}^{\text {ГлК }}+\mathrm{K}+\mathrm{H}\right]^{2+}$ и $m / z 1442,27$ для $\left[6 \mathrm{M}^{\text {Глк }}+\mathrm{K}+\mathrm{Na}\right]^{2+}$. Интенсивности соответствующих пиков были немного выше для $18 \alpha-Г Л К$.

Ассоциаты $18 \alpha$-ГЛК и $18 \beta$-ГЛК, состоящие из 7 катионизированных молекул, также представлены в виде двузарядных катионизированных ионов. Наибольшая интенсивность пика $m / z 1677,51$, а, следовательно, и большая устойчивость в ряду автоассоциатов из 7 молекул ГЛК соответствуют катиону $\left[7 \mathrm{M}^{\Gamma л К}+\mathrm{K}+\mathrm{Na}\right]^{2+}$, причем комплекс более устойчив в случае $18 \alpha-Г Л К$.

В масс-спектре положительных ионов также зафиксированы слабоинтенсивные пики для самоассоциатов, состоящих из 8 молекул ГЛК. Так, идентфицированы пики, соответствующие катионизированным калием и натрием, трехзарядные комплексы из 8 молекул ГЛК в виде трехзарядных катионов. Комплексы в случае $18 \alpha$-ГЛК более устойчивы, чем для $18 \beta$-ГЛК. Только в масс-спектрах $18 \beta$-ГЛК зафиксированы слабоинтенсивные пики $m / z$ 2137,43 и $m / z$ 2148,44 для автоассоциатов из 9 молекул ГЛК $\left[9 \mathrm{M}^{\text {ГлК }}+\mathrm{K}+\mathrm{H}\right]^{2+}$ и $\left[9 \mathrm{M}^{\text {ГлК }}+\mathrm{K}+\mathrm{Na}\right]^{2+}$ соответственно.

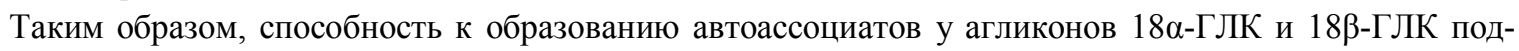
тверждают данные масс-спектрометрии.

Наиболее очевидной причиной аналогичного характера ассоциации агликонов II, III и гликозидаглицирризиновой кислоты I представляется сходное строение молекул этих соединений: димерные ассо- 
циаты по типу «голова к хвосту» с полостью; основное связывание единиц ассоциата обеспечивают карбоксильные группы, расположенные по краям изогнутой молекулы сапонина. Последнее продемонстрировано авторами ранее [8].

Таким образом, на примере стереоизомеров глицирретиновой кислоты II и III впервые показано, что оба стереоизомера по аналогии с тритерпеновыми сапонинами со свободными карбоксильными группами $[8,10]$ могут образовывать автоассоциаты, причем устойчивость этих супрамолекулярных комплексов достаточна для преодоления кулоновского отталкивания.

Следовательно, стереоизомеры глицирретиновой кислоты II и III по аналогии с сапонинами солодки и плюща [8-11] могут стать потенциальной основой для синтеза нового поколения нековалентных молекулярных комплексов и новых высокоэффективных лекарственных субстанций, за счет как возможного улучшения биодоступности [2], так и возможных синергетических эффектов [7].

\section{Заключение}

Масс-спектрометрия с ионизацией электрораспылением использована для изучения процессов формирования автоассоциатов агликона глицирризиновой кислоты - глицирретиновой кислоты.

На примере стереоизомеров глицирретиновой кислоты впервые показано, что оба стереоизомера по аналогии с тритерпеновыми сапонинами со свободными карбоксильными группами могут образовывать автоассоциаты.

Стереоизомеры глицирретиновой кислоты по аналогии с сапонинами солодки и плюща могут стать потенциальной основой для синтеза нового поколения нековалентных молекулярных комплексов и новых высокоэффективных лекарственных субстанций, за счет как возможного улучшения биодоступности, так и возможных синергетических эффектов.

\section{Список литературы}

1. Толстиков Г.А., Балтина Л.А., Шульц Э.Э., Покровский А.Г. Глицирризиновая кислота // Биоорганическая химия. 1997. Т. 23, №9. С. 691-703.

2. Толстикова Т.Г., Толстиков А.Г., Толстиков Г.А. На пути к низкодозным лекарствам // Вестник Российской академии наук. 2007. Т. 77, №10. С. 867-874.

3. Li H.-E., Qiu J.-Z., Yang Z.-Q., Dong J., Wang J.-F., Luo M.-J., Pan J., Dai X.-H., Zhang Y., Song B.-L., Deng X.-M. Glycyrrhetinic acid protects mice from Staphylococcus aureus pneumonia // Fitoterapia. 2012. Vol. 83, N1. Pp. $241-248$.

4. Lai Y., Shen L., Zhang Z., Liu W., Zhang Y., Ji H., Tian J. Synthesis and biological evaluation of furoxan-based nitric oxide-releasing derivatives of glycyrrhetinic acid as anti-hepatocellular carcinoma agents // Bioorganic \& Medicinal Chemistry Letters. 2010. Vol. 20, N22. Pp. 6416-6420.

5. Yamaguchi H., Noshita T., Yu T., Kidachi Y., Kamiie K., Umetsu H., Ryoyama K. Novel effects of glycyrrhetinic acid on the central nervous system tumorigenic progenitor cells: Induction of actin disruption and tumor cell-selective toxicity // European Journal of Medicinal Chemistry. 2010. Vol. 45, N7. Pp. 2943-2948.

6. Krausse R., Bielenberg J., Blaschek W. and Ullmann U. In vitro anti-Helicobacter pylori activity of Extractum liquiritiae, glycyrrhizin and its metabolites // Journal of Antimicrobial Chemotherapy. 2004. Vol. 54, N1. Pp. 243-246.

7. Zhou X., Zhao L., Liu X., Li X., Jia F., Zhang Y., Wang Y. Antimycobacterial and synergistic effects of $18 \beta-$ Glycyrrhetinic acid or glycyrrhetinic acid-30-piperazine in combination with isoniazid, rifampicin or streptomycin against mycobacterium bovis // Phytother. Res. 2012. Vol. 26. P. 253-258.

8. Борисенко С.Н., Лекарь А.В., Милов А.А., Ветрова Е.В., Борисенко Н.И. Масс-спектрометрия и квантовохимическое исследование процессов самоассоциации молекул глицирризиновой кислоты // Химия растительного сырья. 2013. №2. С. 85-92.

9. Лекарь А.В., Ветрова Е.В., Борисенко Н.И., Яковишин Л.А., Гришковец В.И. Масс-спектрометрическое исследование молекулярного комплексообразования растительных гликозидов со стрептоцидом (сульфаниламидом) // Химия растительного сырья. 2011. №2. С. 103-106.

10. Lekar' A.V., Vetrova E.V., Borisenko N.I., Yakovishin L.A., Grishkovets V.I. Mass spectrometric study on plant glycosides molecular complexation with streptocid (sulfanylamide) // Russian Journal of Bioorganic Chemistry. 2012. Vol. 38(7). Pp. 749-752.

11. Lekar' A.V., Yakovishin L.A., Vetrova E.V., Rudnev M.I., Borisenko N.I. Mass Spectrometry of the Self-Association and Complexation of Triterpene Saponins and Cholesterol // Journal of Analytical Chemistry. 2011. Vol. 66. N13. Pp. 4448.

12. Borisenko S.N., Lekar' A.V., Vetrova E.V., Borisenko N.I. Mass Spectrometry of Supramolecular Complexes of Glycyrrhizic Acid and Benzimidazole Derivatives // Chemistry of Natural Compounds. 2013. Vol. 49, N5. Pp. 969-971.

13. Толстикова Т.Г., Сорокина И.В., Брызгалов А.О., Лифшиц Г.И., Хвостов М.В. Использование подхода комплексообразования с глицирризиновой кислотой для создания новых кардиотропных средств // Биомедицина. 2006. №4. С. 115-117. 
Borisenko S.N., Lekar' A.V., Vetrova E.V., Filonova O.V., Borisenko N.I. ${ }^{*}$ MASS SPECTROMETRIC STUDY OF MOLECULES SELF-ASSEMBLY OF GLYCYRRHETINIC ACID

Institute of Physical and Organic Chemistry at Southern Federal University, Stachka Ave., 194/2, Rostov-on-Don, 344090 (Russia), e-mail: boni@ipoc.rsu.ru

Mass spectrometry with the electrospray ionization was used to study the processes of self-association of glycyrrhetinic acid, which is the aglycone of glycyrrhizic acid. It was shown that stereoisomers of glycyrrhetinic acid can form self-associates by analogy with triterpene saponins with the free carboxyl groups. The ability glycyrrhetinic acid to form self-associates was registered in the mass spectra. It has been established that the ionization of associates GLA to form the anion occurs quite weak. At the same time, GLA ionization in the positive ion mode occurs efficiently and allows registering multidimensional structures 1 to 8 molecules of $18 \alpha$-GLA and 1 to 9 molecules of 18ß-GLA. The most comprehensive structure of associates GLA is presented in the mass spectra of positive ions. The results demonstrated the ability of $18 \alpha$ - and18 $\beta$-GLA to form self-associates, and high potential of GLA to form supramolecular complexes. Stereoisomers of glycyrrhetinic as licorice saponins may be a basis for the synthesis of a new generation of non-covalent molecular complexes and new highly medicinal substances for both improvement of bioavailability.

Keywords: self-association, glycyrrhetinic acid, glycyrrhizic acid, mass spectrometry with electrospray ionization, supramolecular complexes.

\section{References}

1. Tolstikov G.A., Baltina L.A., Shults E.E., Pokrovskii A.G. Bioorganicheskaia khimiia, 1997, vol. 23, no. 9, pp. 691-703. (in Russ.).

2. Tolstikova T.G., Tolstikov A.G., Tolstikov G.A. Vestnik Rossiiskoi akademii nauk, 2007, vol. 77, no. 10, pp. 867874. (in Russ.).

3. Li H.-E., Qiu J.-Z., Yang Z.-Q., Dong J., Wang J.-F., Luo M.-J., Pan J., Dai X.-H., Zhang Y., Song B.-L., Deng X.-M. Fitoterapia, 2012, vol. 83, no. 1, pp. 241-248.

4. Lai Y., Shen L., Zhang Z., Liu W., Zhang Y., Ji H., Tian J. Bioorganic \& Medicinal Chemistry Letters, 2010, vol. 20, no. 22, pp. 6416-6420.

5. Yamaguchi H., Noshita T., Yu T., Kidachi Y., Kamiie K., Umetsu H., Ryoyama K. European Journal of Medicinal Chemistry, 2010, vol. 45, no. 7, pp. 2943-2948.

6. Krausse R., Bielenberg J., Blaschek W., Ullmann U. Journal of Antimicrobial Chemotherapy, 2004, vol. 54, no. 1, pp. 243-246.

7. Zhou X., Zhao L., Liu X., Li X., Jia F., Zhang Y., Wang Y. Phytother. Res., 2012, vol. 26, pp. 253-258.

8. Borisenko S.N., Lekar' A.V., Milov A.A., Vetrova E.V., Borisenko N.I. Khimiia rastitel'nogo syr'ia, 2013, no. 2, pp. 85-92. (in Russ.).

9. Lekar' A.V., Vetrova E.V., Borisenko N.I., Iakovishin L.A., Grishkovets V.I. Khimiia rastitel'nogo syr'ia, 2011, no. 2, pp. 103-106. (in Russ.).

10. Lekar' A.V., Vetrova E.V., Borisenko N.I., Yakovishin L.A., Grishkovets V.I. Russian Journal of Bioorganic Chemistry, 2012, vol. 38(7), pp. 749-752.

11. Lekar' A.V., Yakovishin L.A., Vetrova E.V., Rudnev M.I., Borisenko N.I. Journal of Analytical Chemistry, 2011, vol. 66 , no. 13 , pp. $44-48$.

12. Borisenko S.N., Lekar' A.V., Vetrova E.V., Borisenko N.I. Chemistry of Natural Compounds, 2013, vol. 49, no. 5, pp. 969-971.

13. Tolstikova T.G., Sorokina I.V., Bryzgalov A.O., Lifshits G.I., Khvostov M.V. Biomeditsina, 2006, no. 4, pp. 115117. (in Russ.). 